\title{
Special Issue on mine dust research: health effects and control technologies
}

\author{
Shimin Liu ${ }^{1}$ Weimin Cheng ${ }^{2} \cdot$ Gang Wang ${ }^{2} \cdot$ Long Fan $^{1} \cdot$ Rui Zhang ${ }^{1}$
}

Published online: 3 May 2021

(C) The Author(s) 2021

Coal remains one of the principal sources of energy for the world. During the extraction, transport, and processing of coal in underground and surface mining operations, significant amounts of airborne respirable dusts can be generated and released to the working space. Chronic exposure to coal dusts puts the miners at risk for various lung diseases, including coal workers' pneumoconiosis, emphysema, silicosis, and chronic bronchitis. Apart from the miners' lung disease, the coal mine dusts also potentially increase the risk of mine explosion which has been recognized as one of the most severe hazards in underground coal mine. Tremendous efforts have been put globally to reduce respiratory diseases in miners, targeting on reductions in occupational illnesses. However, coal workers' health surveillance data collected from various countries indicates that the prevalence of coal workers' pneumoconiosis has increased during the past decades. The unprecedented levels of progressive massive fibrosis (PMF) can be fatal and have been reported from various coal mine regions. Since most of these lung diseases cannot be cured, the key to occupational respirable disease prevention is to effectively reduce dust exposure. To achieve this objective, the existing dust control technologies should

Shimin Liu

szl3@psu.edu

$\checkmark$ Gang Wang

gang.wang@ sdust.edu.cn

1 Department of Energy and Mineral Engineering, G3 Center and Energy Institute, The Pennsylvania State University, University Park, PA 16802, USA

2 College of Safety and Environmental Engineering, Shandong University of Science and Technology, Qingdao 266590, People's Republic of China be refined, and the innovative dust control technologies need to be explored, developed, and ultimately implemented. Newly emerged and advancing technologies have been widely applied in research to investigate, monitor, identify, characterize, and capture the dusts from the largescale dispersion to invisible nano-scale transmission. The advanced and effective mine dust control technologies are expected to be consistent with the fundamental dust-lung interaction processes that potentially lead to miners' disability. The mine dust research, understood from nanoscale upward, covers a wide range of topics including: (1) multiscale mine dust characterization; (2) control of dust generation; (3) dust toxicity and dust-lung interactions; (4) dilution, dispersion and collection of dust at the in situ mine environment; (5) the intrinsic relationship of geology, hydrology, mining technology to dust generation and transport; (6) mine equipment emitted particulates, diesel particulates and others.

This Special Issue was a collective knowledge amassed by global researchers who have been actively conducted dust-related research in recent years in the exciting and rapidly evolving area of mine health and safety. These papers cover the traditional views of dust control and health related research. Meanwhile, they developed visions for future research directions by introducing the elements necessary for conducting comprehensive, mine-specific research for reducing the exposure of underground miners to dusts and particulate aerosols.

From the perspective of technologies for removing dust in mines, numerical simulation and experiment on the wallmounted swirling ventilation optimized the blowing-tosuction ratio and significantly reduced the respirable dust concentration (Gao et al. 2021). A design of wet scrubbers with 16 blades gave a more than $95 \%$ efficiency for removing total dust and respirable dust (Hu et al. 2021). A 
developed roof bolter drilling control can monitor the drilling efficiency and reduce respirable dust production (Jiang and Luo 2021). By applying foam to the roof area between the coal face and the shield tip, dust concentration from longwall shield movements can be reduced at least $45 \%$ (Reed et al. 2021). These four studies provide thestate-of-the-art dust suppression, elimination and removing technologies from the mine dust source.

From the perspective of the physical and chemical properties of dust in mines, the wettability of copper mine blasting dust is mainly controlled by particle size and pore structure (Jin et al. 2021). A molecular dynamics simulation study indicated that larger coal dust particle has higher wettability (Zhang et al. 2021). A novel chemical composite dust suppressant enhanced the wettability of the hydrophobic coal dust attributed to the reduced solution surface tension (Liu et al. 2021). These three studies emphasize the importance of wettability for dust suppression and the suppression agents should be further refined for the targeted dust suppression.

With the visions of nano-scale dust toxicity and its exposure, a review demonstrated that the quantity and surface area are essential to the toxicity of nano-dust and adverse impacts on health (Fan and Liu 2021). Some questions relating to dust generation, migration, and mitigation were raised, and regulation suggestions were provided. All the studies presented in the Special Issue cover both the innovative engineering control technologies and the dust properties associated with the adverse health effects.

The editorial team could not complete the publication of this Special Issue without the assistance from editors, reviewers and experts from industry and academic fields. We thank these individuals for their efforts on the publication of this Special Issue.

Open Access This article is licensed under a Creative Commons Attribution 4.0 International License, which permits use, sharing, adaptation, distribution and reproduction in any medium or format, as long as you give appropriate credit to the original author(s) and the source, provide a link to the Creative Commons licence, and indicate if changes were made. The images or other third party material in this article are included in the article's Creative Commons licence, unless indicated otherwise in a credit line to the material. If material is not included in the article's Creative Commons licence and your intended use is not permitted by statutory regulation or exceeds the permitted use, you will need to obtain permission directly from the copyright holder. To view a copy of this licence, visit http://creativecommons. org/licenses/by/4.0/.

\section{References}

Fan L, Liu SM (2021) Respirable nano-particulate generations and their pathogenesis in mining workplaces: a review. Int J Coal Sci Technol. https://doi.org/10.1007/s40789-021-00412-w

Gao RZ, Wang PF, Li YJ, Liu RH (2021) Determination of optimal blowing-to-suction flow ratio in mechanized excavation face with wall-mounted swirling ventilation using numerical simulations. Int J Coal Sci Technol. https://doi.org/10.1007/s40789020-00384-3

Hu SY, Yang G, Feng GR, Hu F, Liu CH, Li JH (2021) Experimental study of the dust-removal performance of a wet scrubber. Int $\mathbf{J}$ Coal Sci Technol. https://doi.org/10.1007/s40789-021-00410-y

Jiang H, Luo Y (2021) Development of a roof bolter drilling control process to reduce the generation of respirable dust. Int J Coal Sci Technol. https://doi.org/10.1007/s40789-021-00413-9

Jin LZ, Liu JG, Guo JZ, Wang JY, Wang TY (2021) Physicochemical factors affecting the wettability of copper mine blasting dust. Int J Coal Sci Technol. https://doi.org/10.1007/s40789-021-00411-x

Liu JG, Wang S, Jin LZ, Wang TY, Zhou ZH, Xu JG (2021) Waterretaining properties of $\mathrm{NCZ}$ composite dust suppressant and its wetting ability to hydrophobic coal dust. Int J Coal Sci Technol. https://doi.org/10.1007/s40789-020-00385-2

Reed WR, Shahan MR, Zheng Y, Mazzella A (2021) Laboratory results of foam application testing for longwall shield dust control in a simulated environment. Int $\mathrm{J}$ Coal Sci Technol. https://doi.org/10.1007/s40789-021-00414-8

Zhang Q, Chen XY, Wang HT, Xu CH (2021) Exploration on molecular dynamics simulation methods of microscopic wetting process for coal dust. Int J Coal Sci Technol. https://doi.org/10. 1007/s40789-021-00415-7 